Association for Information Systems AIS Electronic Library (AISeL)

PACIS 1997 Proceedings

Pacific Asia Conference on Information Systems

(PACIS)

December 1997

\title{
Development of a scale for measuring user computer experience
}

Farideh Yaghmaie

University of Wollongong

Rohan Jayasuriya

University of Wollongong

Follow this and additional works at: http://aisel.aisnet.org/pacis1997

\section{Recommended Citation}

Yaghmaie, Farideh and Jayasuriya, Rohan, "Development of a scale for measuring user computer experience" (1997). PACIS 1997 Proceedings. 49.

http://aisel.aisnet.org/pacis1997/49

This material is brought to you by the Pacific Asia Conference on Information Systems (PACIS) at AIS Electronic Library (AISeL). It has been accepted for inclusion in PACIS 1997 Proceedings by an authorized administrator of AIS Electronic Library (AISeL). For more information, please contact elibrary@aisnet.org. 


\title{
Development of a scale for measuring user computer experience
}

\author{
Farideh Yaghmaie and Rohan Jayasuriya \\ University of Wollongong
}

\section{Executive Summary}

The proliferation of computer applications at work has resulted in researchers searching for factors that affect computer performance and usage. One of the factors that has been identified is user computer experience. However there does not seem to be any consensus on the definition or construct. Researchers have either used one-item scales of prior experience or measured the years of experience or number of applications used. Some have recognised the need for multiple measures (Szajna and Mackay, 1995) as it is a multi-dimensional construct. Weil, Rosen, and Wugalter (1990) argued that computer experience measured by such objective measures alone would not necessitate positive attitudes as the subjective nature of experience is important. There is a need for a valid and reliable measure of subjective computer experience for future research on information systems.

The purpose of this study was to develop a scale for measuring subjective computer experience and test its reliability and validity. Item construction was undertaken following a thorough search of the literature, focus groups, interviews with computer experts and users. The subjective computer experience scale (SCES) with 38 Likert-type items was tested for content validity by a panel of ten experts and face validity by fifteen students.

Following these processes the scale was reduced to 25 items. The 25 -item SCES was distributed to 202 second and third year, computer science and business students along with Dambrot's Computer Attitude Scale (CATT). A test-retest of SCES was given to 162 of the same students. Following Principal Component Analysis a 12 item scale with two factors was selected. An Internal Consistency reliability of 0.97 and 0.66 and a test-retest reliability of 0.80 or 0.65 was found for the two factors. The two factors correlate with the CATT scale of 0.62 and 0.36 respectively.

A useful measure of subjective computer experience has been developed but it needs further validation in different settings.

\section{Significance of the Study}

The proliferation of computer applications at work creates a particular interest and concern about user experience. Computer experience prepares users to participate effectively in a computer-dependent society. Much of the literature shows that computer experience has been used as an independent variable to predict computing performance (Szajna and Mackay, 1995), computer usage (Igbaria, 1990; Taylor and Todd, 1995) and computer attitudes/anxiety (Dambrot et al, 1985; Kernan and Howard, 1990, Heinssen, Glass and Knight, 1987; Leach and Caputi, 1995). Davis (1993) states that future research should investigate user computer experience as an important variable in information systems.

Different instruments and methods have been used to identify computer experience in the literature. At one extreme a single item scale has been used (Harrington, Elory and Morrow, 1990; Abdul-Gader; 1996) others have used multiple scales have been used (Koslowsky, Hoffman and Lazar, 1990; Szajna and Mackay, 1995; Leach and Caputi, 1995). Authors of the latter type of measures have argued that as computer experience is measured in a different manner by researchers multiple scales are needed to make comparisons (Szajna and Mackay, 1995) and that it is too simplistic to consider that computer experience is only a measure of years of experience and number of applications used (Leach and Caputi, 1995). The number of years or the frequency of use of computers cannot provide sufficient information in relation to the quality of computer experience. In some situations, persons with a few years of-computer-experience-may have high quality_experience and vice versa. Some items of scales are based on experience in playing games (Sancho et al., 1993), user participation in computer courses, use of home computers (Colley, Gale and Harris, 1994) and experience of using a computing resource centre (Taylor and Todd, 1995). In contrast to such single item measures, Szajna and Mackay (1995) used an index based on subjects level of participation in computer-related activities, 
extent of use of types of software, number of computer related classes taken and the number of computer languages that the subject was familiar with. Schwiran et al. (1989) assessed nursing student's experience with computers based on a number of measures that included items such as (i) Do you currently own a computer? (ii) In your work experience have you used a computer (iii) In your education have you had experience with programming?

Most of the above studies have operationalised computer experience as an objective measure. Weil, Rosen and Wugalter (1990) argued that computer experience measured by such objective measures alone would not necessitate positive attitudes as the subjective nature of the experience, the perception whether the experience is positive or negative is important. Subjective computer experience is the perception of users in relation to computer experience that only they can explain. Given the importance of the relationship of attitudes to computer performance and usage, (Taylor and Todd, 1995) it is necessary that subjective measures of computer experience are included. Leach and Caputi (1995) developed a Qualitative Computer Experience Questionnaire (QCEQ) which included only one item on the quality of the experience. They concluded that the inclusion of the subjective scale showed that it was more important than the amount of experience in forming attitudes towards computers (Leach and Caputi, 1995). Therefore the need for a valid and reliable instrument to measure this important variable is required.

\section{Developing an instrument to measure computer experience}

The intention of this component of the study was to develop a scale for measuring subjective computer experience and test its reliability and validity. The development of the scale is described under (i) item construction and item selection and (ii) psychometric evaluation of the scale.

\section{(i) item construction and item selection}

The items for inclusion in the scale were selected based on a definition developed by one author (F.Y) that subjective computer experience is a 'perception and judgement of users regarding the processes of gaining computer knowledge and skills through the involvement of all senses and activities of users'. To obtain further information two focus groups of academics (11 persons) and interviews with expert users ( 6 persons) of computerised systems in the local health service were conducted. The purposes of the focus groups were to find the perspective of the groups on the understanding of 'computer experience' and to identify the dimensions of computer experience. Based on the literature and the group work a list of 38 items were identified by one author (F.Y) on subjective computer experience. The items were then constructed for Likert scales anchored at end points with $1=$ strongly agree and $5=$ strongly disagree.

To test the content validity of the SCES, the researcher selected ten experts from the Health Service and the University. The experts were asked to rate each item based on relevance, clarity, simplicity and ambiguity on a four-point scale. The Index of Content Validity (CVI) (Waltz and Bausell, 1983) was calculated for relevance of the items. The items that had CVI over 0.75 remained and other items discarded. The scores on determine the clarity simplicity and ambiguity of each item were used to identify items requiring modification. The scale was reduced to 25 items in this process. Face validity was ascertained by administering it to 15 students.

\section{(ii) psychometric evaluation of the scale.}

The psychometric tests were applied to the instrument for the purposes of refining the instrument and for testing its reliability and validity: Further tests are planned to be undertaken to test its reliability and validity in the main study. The tests reported are (i) factor analysis (ii) reliability (internal consistency and test-retest reliability) and (iii) and concurrent validity of the instrument.

For these tests the instrument was distributed to 209 second and third year computer science and business systems students of the university. The response rate of $202(97 \%)$ was obtained.

The factor structure matrix for this revised scale was based on Principal Component Analysis with varimax orthogonal rotation. A two factor solution was selected based on a Scree test Using a cut off of 0.5 for factor loading five items were deleted to reduce the scale to 20 item scale. 
Reliability

The most common method of testing a scale's reliability is to estimate the Cronbach's Alpha coefficient (Nunnally, 1978). For determining the stability of the instrument a test-retest was carried out. The SCES was administrated again after three weeks, to the same group of computer science and business students at the university. The numbers of participants for the retest were 162 . The responses of the students in the test and retest were matched and Pearson's Correlation calculated.

Based on the results of test-retest, some unreliable items from factor 1 (four items) and from factor 2 (four items) were removed reducing the scale to 12 items. The final SCES is given in Table 1. The reliability's for the two factors are given in Table 2.

Table 1: Subjective Computer Experience Scale (SCES): Varimax-Rotated factor pattern for Principal Component Analysis

\begin{tabular}{|c|l|l|l|}
\hline $\begin{array}{c}\text { Item } \\
\text { No }\end{array}$ & Item stem & $\begin{array}{l}\text { Factor } \\
1\end{array}$ & $\begin{array}{l}\text { Factor } \\
2\end{array}$ \\
\hline 9 & 'I really enjoy using computers'. & 0.785 & \\
\hline 15 & 'I enjoy using a computer now that I have learned how to use computers'. & 0.771 & \\
\hline 25 & 'In general, my feeling towards computers is positive'. & 0.735 & \\
\hline 3 & 'I have skills to use Electronic-mail (E-mail)'. & 0.646 & \\
\hline 19 & 'Computer training gives me confidence to use computers'. & 0.635 & \\
\hline 1 & 'I have knowledge about one or more computer programming languages'. & 0.614 & \\
\hline 7 & 'I feel confident about using computers'. & 0.605 & \\
\hline 21 & 'Having self-confidence helps me to learn computer skills easily'. & 0.579 & \\
\hline 11 & 'I feel that I have failed if I can't use computers'. & & 0.662 \\
\hline 18 & 'Computer jargon makes me afraid to learn about computers'. & & 0.662 \\
\hline 14 & 'I become frustrated when I don't have skills to use certain programs' & & 0.633 \\
\hline 10 & 'When I don't know how to use computers I become frustrated'. & & 0.627 \\
\hline & & & \\
\hline & Eigen Values & 3.27 & 2.51 \\
\hline & $\%$ of Total Variance explained & 35.6 & 20.9 \\
\hline & $\%$ of Common variance explained & 63.0 & 37.0 \\
\hline
\end{tabular}


Table 2

Results of Cronbach's Alpha Coefficient and Test-Retest Analysis for Each Factor (12 items).

Factor Cronbach's Alpha Test-Retest

$\begin{array}{lll}\text { Factor } 1(8 \text { items) } & .97 & .80\end{array}$

$\begin{array}{lll}\text { Factor } 2 \text { (4 items) } \quad .66 & .65\end{array}$

\section{Concurrent validity}

Concurrent validity is assessed by comparing test or scale scores with one or more criteria (e.g score of computer experience with score of computer attitude) where both variable are measured at the same time (Kerlinger, 1986). Concurrent validity of SCES was measured by relating it to Computer Attitude Scale (CATT) that has developed by Dambrot et al. (1985). In Dambrot's study computer experience was found to significantly correlate with the CATT $(r=0.19)$.

The CATT was distributed to the original 202 students of computer science and business students with the administration of the SCES instrument. The results are presented in Table 3.

Table 3

Person's Correlations for Factors of CE and CATT

\begin{tabular}{lll}
\hline Factors & CATT & $P$ \\
\hline Factor 1 & 0.62 & 0.0001 \\
Factor 2 & 0.36 & 0.0001
\end{tabular}

\section{Conclusions and further work}

The literature on computer experience indicates that many different measures are used in research to operationalise this important variable. The need for a subjective measure of computer experience has been espoused by Weil, Rosen, and Wugalter (1990) as this relates to the notion that not all experience is positive. Using standard methods a scale was developed with 12 items and two factors. The internal consistency of the factors were 0.97 ( 8 items) and 0.66 (4 items) and the test-retest reliability was 0.80 and 0.65 respectively. The items in factor 1 reveal subjective computer experience to relate to 'confidence-skills-enjoyment' while factor 2 seems to tap 'failure-fearfrustration'. It seems that while the first factor taps positive experience the latter taps negative feelings. However the internal consistency and test-retest reliability are not as good as factor one and it needs further validation.

The scale was compared with the Dambrot's computer attitude scale to test concurrent validity. While the factor one shows that it relates to computer attitude factor 2 is not highly correlated. This may indicate that negative subjective experience is different to computer attitudes.

Further work to test the factor structure using confirmatory factor analysis, relationship of this scale with computer attitudes and subjective norm is planned. Further research is needed to clarify the underlying constructs and to test its construct validity.

\section{Acknowledgements}

The authors would like to acknowledge the assisstance of Anne Proter and Vicki Blanch in the data analysis. They would like to thank all the participants from the University and the Illawarra Area Health service for their cooperation. 


\section{References}

Abdul-Gader, A. (1996), The impact of user satisfaction on Computer-Mediated Communication Acceptance: A causal path model. Information Resources Management Journal 9 (1), 17-26.

Colley, A. M., Gale, M. T. and Harris, T. A. (1994), Effects of gender role identify and experience on computer attitude components. J. Educational Computing Research 10 (2), 129-137.

Dambrot, F. H., Watkins-Malek, M. A., Silling, S. M., Marshall, R. S. and Garver, J. A. (1985), Correlates of sex differences in attitudes towards and involvement with computers. Journal of Vocational Behaviour 27 (1), $71-86$.

Davis, F. D. (1993), User acceptance of information technology: System characteristics, user perceptions and behavioural impacts. Int. J. Man-Machine Studies 38 (3), 475-487.

Harrington, K. V., Mc Elroy, J. C. and Morrow, P. C. (1990), Computer anxiety and computer-based training: A laboratory experiment. J. Educational Computing Research 6 (3), 343-358.

Heinssen, R. K.; Glass. C. R. and Knight, L. A. (1987). Assessing computer anxiety: Development and validation of the computer anxiety rating scale, Computers in Human Behaviour. $3,49-59$.

Igbaria, M. (1990), End-user computing effectiveness: A structural Equation Model. OMEGA 18 (6), 637-652. Kerlinger, F. N. (1986), Foundations of Behavioural Research. Third Edition. CBS Publishing Japan, New York. Kernan. M. C. and Howard, G. S. (1990), Computer anxiety and computer attitudes: An investigations of construct and predictive validity issues. Educational and Psychological Measurement_50, 681-690.

Koslowsky, M., Hoffman, M. and Lazar, A. (1990), Predicting behaviour on a computer from intentions, attitudes and experience. Current Psychological: Research and Reviews 9 (1), 75-83.

Leach, K. and Caputi, P. (1995), Students Attitudes to Computers: personality type, Gender, Cognitive ability, and Computer Experience. Swinburne University of Technology.

Nunnally, J. C. (1978), Psychometric Theory Second Edition, McGraw-Hill Book Company, New York.

Sancho, J. J. Gonzalez, J. C., Patak, A., Sanz, F. and Sitges-Serrat, A. (1993), Introducing medical students to medical informatics. Medical Education 27 (6), 479-483.

Schwiran, P.M., Malone, J.A., Stone, V.J., Nunley, B. and Francisco, T. (1989), Computers in Nursing Practice: A comparison of the attitudes of nurses and nursing students. Computers in Nursing 7(4), $168-177$.

Szajna, B. and Mackay, J. M. (1995), Predictors of Learning performance in a computer-user training environment: A path-Analytic study. International Joumal of Human-Computer Interaction 7(2), 167-185.

Taylor, S. and Todd, P. (1995), Assessing IT usage: the role of prior experience. MIS Quarterly 561-570.

Waltz, C. F. and Bausell, R. B. (1983). Nursing Research: Design, Statistics and Computer Analysis. Second edition, F. A. Davis Company, Philadelphia.

Weil, M. M.; Rosen, L. D. and Wugalter, S. E. (1990), The etiology of computerphobia, Computers in Human Behaviour. 6, 361-379. 